\title{
MATRIK
}

Jurnal Manajemen dan Teknik Industri-Produksi

Journal homepage: http://www.journal.umg.ac.id/index.php/matriks

\section{Pengukuran Kinerja Menggunakan Metode Balanced Scorecard dan Analytical Network Process Pada Perusahaan}

\section{Adhi Nugraha1, Muhammad Abdillah Arif ${ }^{2}$, Dr. Ahmad Mubin ${ }^{3}$}

Jurusan Teknik Industri, Fakultas Teknik Universitas Muhammadiyah Malang

Jl. Bendungan Sutami No.188, Kota Malang, Jawa Timur, Indonesia

Timuradhinugraha@umm.ac.id

\begin{tabular}{l} 
INFO ARTIKEL \\
\hline $\begin{array}{c}\text { doi: } \mathbf{1 0 . 3 5 0 5 8 7 / M a t r i k} \\
\text { v18i2.589 }\end{array}$ \\
\hline Jejak Artikel : \\
Upload artikel \\
O2 Oktober 2019 \\
Revisi oleh reviewer \\
27 Februari 2020 \\
Publish \\
30 Maret 2020 \\
\hline
\end{tabular}

Kata Kunci :

Balanced Scorecard, Analytical

Network Process, Key

Performance Indicator

\section{ABSTRAK}

Pengukuran kinerja yang selama ini digunakan oleh sebuah perusahaan manufaktur lampu, hanya fokus pada aspek keuangan saja, sehingga aspek - aspek lain diantaranya aspek pelanggan, aspek proses bisnis internal, dan aspek pembelajaran \& pertumbuhan masih belum terukur. Perusahaan perlu merancang suatu metode pengukuran kinerja untuk dapat mengetahui tingkat kinerja perusahaan saat ini, yang juga bisa digunakan sebagai acuan perbaikan dan peningkatan kinerja yang harus dilakukan perusahaan. Permasalahan yang dialami perusahaan terdapat pada aspek keuangan, pelanggan, proses bisnis internal, serta pembelajaran dan pertumbuhan. Dalam penyelesaian masalah kinerja, peneliti menggunakan model Balanced Scorecard untuk perancangan serta Analytical Network Process (ANP) untuk pembobotan indikator kinerja. Adapun untuk pengukuran kinerja perusahaan menggunakan Objective Matrix dengan evaluasi menggunakan Traffic Light System. Dengan menggunakan beberapa metode tersebut, didapatkan beberapa Key Performance Indicator (KPI) yang dianggap kurang yaitu tingkat kepuasan pelanggan (customer satisfaction index), jumlah produksi tiap periode, tingkat efisiensi produksi, jumlah pelatihan kompetensi karyawan, dan tingkat produktifitas karyawan per periode. 


\section{Pendahuluan}

Ketatnya persaingan di dunia industri saat ini mendorong perusahaan manufaktur untuk meningkatkan aspek kinerja perusahaan mereka demi menghasilkan keunggulan kompetitif. Peningkatan aspek kinerja yang dimaksud adalah dengan mengembangkan bisnis perusahaan mereka agar dapat bersaing dengan perusahaan lainnya. Selain itu, para pelaku perusahaan juga bekerja keras untuk menarik konsumen mereka dengan berbagai cara. Objek penelitian merupakan perusahaan yang bergerak dibidang manufaktur berupa produk lampu. Banyaknya kebutuhan produk lampu membuat perusahaan harus memproduksi produk secara terus-menerus sesuai dengan kebutuhan tiap harinya. Dengan adanya kegiatan produksi yang terus-menerus, maka perusahaan perlu melakukan kontrol atau pengawasan pada berbagai aspek untuk meningkatkan kinerja perusahaan.

Pada sebuah perusahaan manufaktur lampu, beberapa hal terkait sistem pengukuran kinerja ini dianggap masih belum optimal. Adapun permasalahan yang dialami oleh perusahaan adalah masih belum terlaksananya proses pengukuran kinerja secara terpadu. Hal ini disebabkan oleh pengukuran kinerja yang saat ini digunakan pada perusahaan masih terbatas pada aspek keuangan, dan belum mencakup pada aspek lainnya. Dengan adanya permasalahan ini, maka penulis berusaha untuk menyelesaikannya dengan menggunakan metode Balanced Scorecard dan metode Analytical Network Process dengan harapan agar dapat memberikan solusi terbaik bagi perusahaan.

Model Balanced Scorecard (BSC) serta model Analytic Network Process (ANP) pada dasarnya merupakan metode yang sering digunakan untuk mengatasi masalah pengukuran kinerja terutama aspek keuangan yang sering digunakan oleh sebuah perusahaan. Balanced Scorecard berfungsi untuk menyeimbangkan dan mengelolasegala yang berhubungan dengan perusahaan secara kompleks dan komprehensif suatu perusahaan, sehingga tidak hanya mengukur tentang biaya yang dimiliki perusahaan. Konsep ini akan mengukur aktivitas-aktivitas operasional suatu perusahaan pada skala kecil agar sesuai dan sejalan dengan sasaran perusahaan yang lebih besar menurut visi dan strateginya. Metode Balanced Scorecard juga akan membantu perusahaan untuk menyelesaikan 2 permasalahan fundamental, yaitu secara efektif mengukur performa organisasi serta implementasi strategi secara sukses. Sedangkan Analytic Network Process adalah suatu metode yang mempresentasikan hubungan beberapa pihak terkait dengan memperhatikan tingkat kepentingan secara objektif serta mempertimbangkan hubungan keterkaitan suatu kriteria dengan sub kriteria yang ada. Beberapa penelitian terdahulu telah membahas mengenai penggunaan Balanced Scorecard dan ANP dalam peningkatan kinerja perusahaan. [1] membahas aplikasi Analytic Network Process (ANP) untuk mendukung pembobotan pada perancangan sistem pengukuran kinerja dengan metode Balanced Scorecard.[2] melakukan pengukuran kinerja menggunakan metode Balanced Scorecard dan ANP pada perusahaan bidang pengecoran dan permesinan. Dan[3] melakukan penelitian mengenai aplikasi ANP pada perancangan sistem pengukuran kinerja dengan menggunakan metode balanced scorecard. Dari penelitian terdahulu, belum ada penelitian yang mengambil studi kasus pada perusahaan manufaktur lampu. Tujuan penelitian ini adalah mengetahui bagaimana aplikasi Analitical Network Process pada pengukuran kinerja dengan menggunakan metode balance scorecard di perusahaan manufaktur lampu

\section{Metode Penelitian}

\subsection{Balanced Scorecard}

Metode Balanced Scorecard merupakan salah satu metode untuk mengukur kinerja sebuah perusahaan. Metode ini pertama kali diperkenalkan oleh David Norton, CEO Nolan Norton Institute, dan Robert Kaplan, seorang profesor di Harvard University [4]. Dalam pengukurannya, metode ini mencakup empat 
perspektif yang dimana keempatnya dianggap sangat berpengaruh penting terhadap pengukuran kinerja.

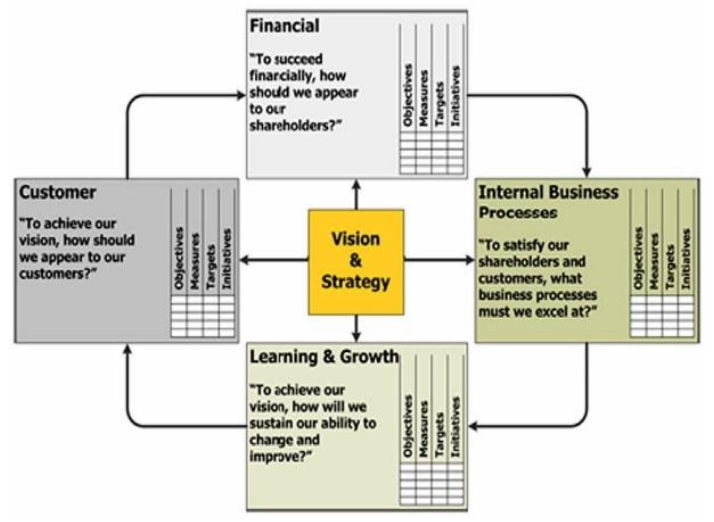

Gambar 1. Perspektif Balanced Scorecard

Keempat perspektif tersebut yaitu keuangan, customer, proses bisnis internal, serta pertumbuhan dan pembelajaran dapat divisualisasikan dalam Gambar 1. Dari keempat perspektif tersebut, maka akan didapatkan visi dan strategi dari perusahaan.

Aspek keuangan merupakan salah satu hal terpenting bagi berjalannya suatu kegiatan pada sebuah perusahaan. Aspek keuangan sendiri selalu berhubungan dengan pemasukan dan pengeluaran dari perusahaan. Sehingga perusahaan harus mampu mengelola dan memanajemen sumber keuangan agar tetap stabil dalam proses kegiatannya.

Pelanggan merupakan indikator penting perusahaan untuk mengukur kinerja mereka. Semakin banyak pelanggan yang menggunakan produk maupun jasa yang dimiliki perusahaan, maka perusahaan tersebut semakin baik. Hal ini dikarenkan pelanggan merupakan pihak yang dapat menilai hasil kinerja perusahaan. Dalam hal ini, penilaian dari pelanggan dapat dilihat dari loyalitas pelanggan untuk mempertahankan produk maupun jasa dari perusahaan. Sebuah produk akan dinilai baik jika produk tersebut memiliki manfaat yang diharapkan oleh pelanggan. Perspektif ini pun terbagi menjadi 2 jenis kelompok pengukuran, yaitu customer core measurement dan customer value prepositions[5].

Pada internal business, penggunaan Balanced Scorecard bertujuan agar perusahaan dapat mengetahui apakah proses bi MATRIK :Jurnal Manajemen \& Teknik Industri - Produksi Volume XX, No.2, Maret 2020, Halaman XX-XX

snis berjalan dengan baik serta mengetahui apakah produk yang diproduksi telah sesuai dengan keinginan pelanggan. Dalam hal ini, perusahaan harus pandai dalam melakukan strateginya. Hal ini dikarenakan selain agar mereka dapat menarik minat pelanggan, mereka juga harus mengalahkan pesaing dari perusahaan sejenis. Proses bisnis internal sendiri terbagi menjadi 3 tahapan [3], yaitu proses inovasi, proses operasi, dan proses purna jual.

Setelah adanya ketiga proses yang ada di atas, maka tahap selanjutnya adalah pertumbuhan dan pembelajaran dimana sebuah perusahaan mengevaluasi hasil dari kegiatan mereka dari awal hingga periode tertentu. Pembelajaran dalam hal ini dilakukan untuk mengetahui kekurangan-kekurangan dan permasalahan yang ada selama proses operasi perusahaan. Selain itu, dalam hal ini perusahaan dapat melakukan pembaruan strategi agar dapat bersaing dengan perusahaan lainnya.

\subsection{Analytical Network Process}

Model ini merupakan hasil dari perkembangan model AHP (Analytical Hierarchy Process) yang mampu mengakomodasi keterkaitan antar kriteria dan alternative [6] . Penggunaan model ANP ini dianggap lebih baik dibandingkan penggunaan model AHP. Hal ini dikarenakan model ANP yang dapat merepresentasikan tingkat kepentingan berbagai pihak dengan mempertimbangkan saling keterkaitan antar kriteria dan sub kriteria yang ada. Sehingga model ini dianggap lebih kompleks dibandingkan menggunakan model AHP.

Dalam penggunaannya, keterkaitan pada model ini terbagi menjadi 2 jenis, yaitu keterkaitan dalam satu set elemen (innerdependence) serta keterkaitan dalam elemen yang berbeda (outerdependence). Sistem pembobotan ANP harus membutuhkan model yang dapat mempresentasikan hubungan keterkaitan antara kriteria dengan subkriteria 
yang dimiliki oleh model tersebut. Adapun mengenai sistem kontrol pada model ini terbagi menjadi 2, yaitu kontrol hierarki yang menunjukkan keterkaitan kriteria dengan subkriteria dan kontrol keterkaitan yang menunjukkan adanya saling keterkaitan antara kriteria satu dengan kriteria lainnya [7]]. Adapun tahapan dalam pengolahan metode ANP terbagi menjadi beberapa langkah, yaitu sebagai berikut:

1. Pembobotan ANP

2. Penentuan bobot prioritas

3. Penentuan ranking alternatif

4. Pemilihan hasil ranking

Setelah dilakukan pembobotan pada tiap KPI, maka selanjutnya dilakukan pengukuran. Dalam pengukuran ini, hasil dari perancangan akan dibandingkan dengan keadaan real perusahaan sebelum adanya perancangan. Beberapa aspek yang akan diukur adalah aspek keuangan, pelanggan, pertumbuhan, serta proses bisnis internal. Pengukuran ini bertujuan agar dapat mengetahui target perusahaan. Jika hasil pengukuran setelah perancangan dinilai masih kurang, maka akan dilakukan evaluasi untuk melakukan perancangan ulang agar lebih baik. Adapun langkah-langkah dalam pengukuran adalah sebagai berikut:

a. Menetapkan tujuan

Pada langkah ini, tujuan bertujuan untuk mengetahui sesuatu yang ingin dicapai organisasi serta menjadi pedoman dalam perumusan kriteria kinerja perusahaan.

b. Merumuskan indikator dan ukuran kerja

Perumusan indikator dan ukuran kerja yang mengacu pada penilaian kinerja secara langsung.

c. Pelaporan hasil pengukuran kinerja

Dalam proses pengukuran kinerja, maka metode OMAX digunakan untuk mengetahui nilai pencapaian dari masing-masing KPI yang telah ditentukan. Metode ini dapat menggabungkan kriteria-kriteria produktifitas kedalam suatu bentuk yang terpadu dan berhubungan satu sama lain. Model ini juga melibatkan seluruh jajaran perusahaan mulai dari bawahan hingga atasan. Adapun skema penilaian OMAX dirujuk pada gambar 3.2. dengan 3 bagan skema penilaian yaitu Defining,Quantifying, dan Monitoring .

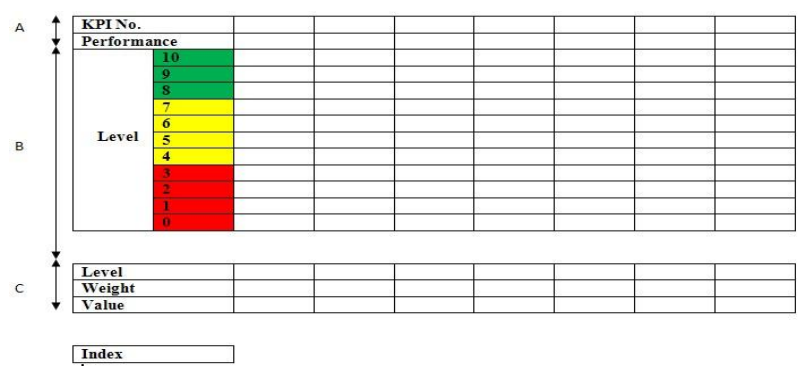

Gambar 2. Kerangka matriks OMAX

\subsection{Traffic Light System (TLS)}

TLS digunakan sebagai indikator Score KPI memerlukan suatu perbaikan atau tidak yang direpresentasikan dengan beberapa warna sebagai berikut:

a. Warna hijau

Indikator telah mencapai kinerja yang telah diinginkan. Range penilaian warna hijau adalah 8-10.

b. Warna kuning

Indikator kinerja masih belum tercapai atau belum sesuai dengan tujuan. Range penilaian warna kuning adalah 4-7

c. Warna merah

Indikator kinerja di bawah target yang ditentukan. Range penilaian warna merah adalah 0-3.

Objek penelitian merupakan perusahaan yang bergerak dibidang manufaktur yang lampu. Dalam penelitian ini, beberapa data diperlukan untuk menunjang pengolahan data dalam memecahkan masalah yang terdapat di perusahaan. Data-data tersebut terdiri dari data primer dan data sekunder. Data primer yang dibutuhkan dalam penelitian ini terdiri dari jumlah produksi, jumlah karyawan, kinerja karyawan, mesin, dan beberapa data lainnya. Pada kinerja karyawan, mesin, dan beberapa data yang bersifat kualitatif didapatkan berdasarkan hasil wawancara yang dilakukan kepada pegawai perusahaan. Sedangkan data sekunder merupakan data yang berhubungan tentang perusahaan, dimana data ini merupakan data penunjang dalam penelitian. 


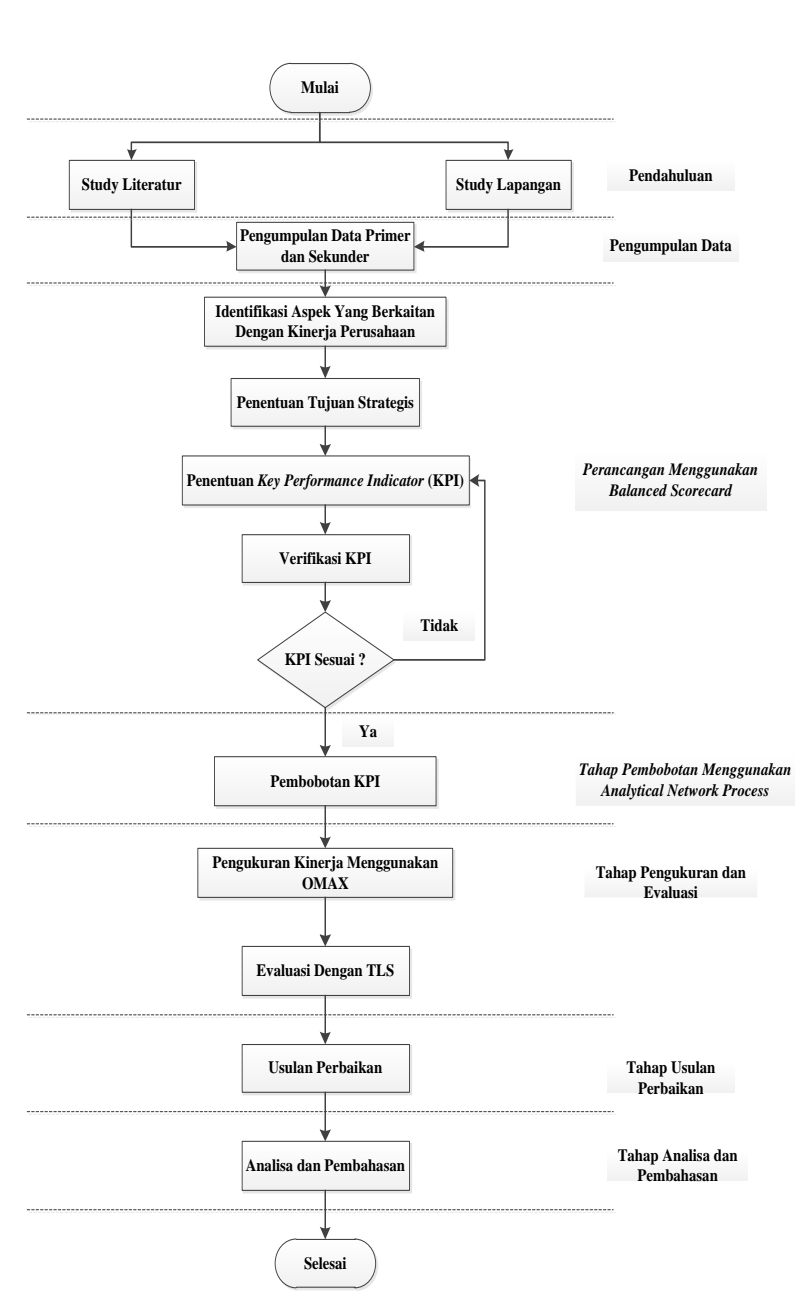

Gambar 3.Flowchart MetodologiPenelitian

\section{Hasil dan Pembahasan}

\subsection{Perancangan Dengan Model Balanced Scorecard}

Dalam perancangan menggunakan metode BSC, terdapat beberapa tahapan yaitu penentuan tujuan strategis, penentuan KPI, dan verifikasi KPI.

\subsection{Penentuan Strategis}

Berdasarkan visi dan misi, serta hasil identifikasi aspek yang telah dilakukan, maka dapat ditentukan tujuan strategi seperti pada tabel 1 mengenai tujuan strategi.

Tabel 1. Tujuan Strategis Perusahaan

\begin{tabular}{|c|l|}
\hline \multicolumn{1}{|c|}{ Aspek } & \multicolumn{1}{|c|}{ Tujuan Strategis } \\
\hline $\begin{array}{l}\text { Perspektif } \\
\text { Financial }\end{array}$ & $\begin{array}{l}\text { F1 Peningkatan profitabilitas } \\
\text { perusahaan }\end{array}$ \\
\hline
\end{tabular}

\begin{tabular}{|c|c|}
\hline \multirow{2}{*}{$\begin{array}{l}\text { Perspektif } \\
\text { Customer }\end{array}$} & $\begin{array}{l}\text { C1 Meningkatkan jumlah } \\
\text { pelanggan baru }\end{array}$ \\
\hline & $\begin{array}{l}\text { C2Mempertahankan pelanggan } \\
\text { lama }\end{array}$ \\
\hline \multirow{4}{*}{$\begin{array}{l}\text { Perspektif } \\
\text { Internal } \\
\text { Business }\end{array}$} & I1 Peningkatan kapasitas produksi \\
\hline & I2 Peningkatan kualitas produk \\
\hline & I3 Peningkatan utilitas mesin \\
\hline & I4 Peningkatan efisiensi produksi \\
\hline \multirow{4}{*}{$\begin{array}{l}\text { Perspektif } \\
\text { Learning and } \\
\text { Growth }\end{array}$} & $\begin{array}{lll}\text { L1 Peningkatan } & \text { kompetensi } \\
\text { karyawan } & \end{array}$ \\
\hline & $\begin{array}{l}\text { L2 Peningkatan lingkungan kerja } \\
\text { kondusif }\end{array}$ \\
\hline & $\begin{array}{lll}\text { L3 } & \text { Peningkatan } & \text { produktifitas } \\
\text { karyawan } & \end{array}$ \\
\hline & $\begin{array}{l}\text { L4 Peningkatan kesejahteraan } \\
\text { karyawan }\end{array}$ \\
\hline
\end{tabular}

Sumber: Hasil Pengolahan Data 2019

Berdasarkan pada tabel 1, dapat diketahui bahwa pada aspek financial terdapat 2 KPI, pada aspek customer terdapat 2 KPI, aspek internal business dengan $4 \mathrm{KPI}$, serta aspek learning and growth dengan 4 KPI pula.

\subsection{Penentuan KPI}

Berdasarkan tujuan strategis yang telah disusun, maka didapatkan beberapa Key Performance Indicator (KPI) yang dianggap berpengaruh oleh perusahaan. Dari keempat aspek yang ada, aspek keuangan dianggap baik meskipun diperlukan peningkatan lagi.

Berdasarkan dari gambar 1, maka permasalahan-permasalahan yang dialami oleh perusahaan kemudian akan diolah untuk mencari faktor pengaru perusahaan. Dalam hal ini, penyusunan KPI dilakukan untuk mengetahui indicator dari keempat aspek yang ada. Dalam penentuan KPI, maka beberapa faktor ditentukan dengan merujukpada empat aspek yang telah ditentukan. Adapun KPI yang telah ditentukan seperti pada tabel 2.

Tabel 2. Key Performance Indicator

\begin{tabular}{|l|l|}
\hline Tujuan Strategis & Key Performance Indicators \\
\hline $\begin{array}{l}\text { F1 Peningkatan } \\
\text { profitabilitas }\end{array}$ & Rasio Profitabilitas \\
\hline $\begin{array}{l}\text { F2 Peningkatan } \\
\text { likuiditas } \\
\text { perusahaan }\end{array}$ & Current Ratio per periode \\
\cline { 2 - 2 } & Acid Test Ratio per periode \\
\hline
\end{tabular}




\begin{tabular}{|c|c|}
\hline $\begin{array}{l}\text { C1 Meningkatkan } \\
\text { jumlah pelanggan } \\
\text { baru }\end{array}$ & Persentase pelanggan baru \\
\hline \multirow{2}{*}{$\begin{array}{l}\text { C2 } \\
\text { Mempertahankan } \\
\text { pelanggan lama }\end{array}$} & Customer satisfaction index \\
\hline & Persentase pelanggan tetap \\
\hline $\begin{array}{l}\text { I1 Peningkatan } \\
\text { kapasitas produksi }\end{array}$ & Jumlah produksi tiap periode \\
\hline $\begin{array}{l}\text { I2 Peningkatan } \\
\text { kualitas produk }\end{array}$ & Jumlah kecacatan produk \\
\hline \multirow{2}{*}{$\begin{array}{l}\text { I3 Peningkatan } \\
\text { utilitas mesin }\end{array}$} & $\begin{array}{l}\text { Overall } \\
\text { effectiveness }\end{array}$ \\
\hline & Jam kerja mesin \\
\hline $\begin{array}{ll}\text { I4 } & \text { Peningkatan } \\
\text { efisiensi produksi }\end{array}$ & Tingkat efisiensi Produksi \\
\hline $\begin{array}{l}\text { L1 Peningkatan } \\
\text { kompetensi } \\
\text { karyawan }\end{array}$ & $\begin{array}{l}\text { Jumlah pelatihan kompetensi } \\
\text { karyawan }\end{array}$ \\
\hline \multirow{2}{*}{$\begin{array}{l}\text { L2 Peningkatan } \\
\text { lingkungan kerja } \\
\text { kondusif }\end{array}$} & Persentase karir kayawan \\
\hline & $\begin{array}{ll}\text { Sistem komunikasi } & \text { dari } \\
\text { karyawan hingga atasan } & \end{array}$ \\
\hline $\begin{array}{l}\text { L3 Peningkatan } \\
\text { produktifitas } \\
\text { karyawan }\end{array}$ & $\begin{array}{l}\text { Tingkat produktifitas } \\
\text { karyawan per periode }\end{array}$ \\
\hline $\begin{array}{l}\text { L4 Peningkatan } \\
\text { kesejahteraan } \\
\text { karyawan }\end{array}$ & Jaminan kesehatan karyawan \\
\hline
\end{tabular}

Sumber: Hasil Pengolahan Data 2019

\subsection{Verifikasi KPI}

Proses verivikasi dalam penentuan KPI dilakukan berdasarkan hasil yang telah ditentukan oleh peneliti dan disetujui oleh pihak perusahaan. Dalam penentuannya, didapatkan sebanyak 16 KPI. Verifikasi yang dilakukan berdasarkan indikator-indikator yang telah ditentukan sebelumnya. KPI yang telah didapatkan selanjutnya akan dilakukan proses pemboobotan untuk mengetahui KPI mana yang paling utama.

Tabel 3. Verifikasi KPI

\begin{tabular}{|l|l|l|l|}
\hline \multirow{2}{*}{$\begin{array}{l}\text { Tujuan } \\
\text { Strategis }\end{array}$} & $\begin{array}{l}\text { Key } \\
\text { Performa } \\
\text { nce } \\
\text { Indicators }\end{array}$ & KPI yang Disetujui \\
\cline { 3 - 4 } & Kode & $\begin{array}{l}\text { Key } \\
\text { Performa } \\
\text { nce } \\
\text { Indicators }\end{array}$ \\
\hline $\begin{array}{l}\text { F1 } \\
\text { Peningkatan } \\
\text { profitabilitas }\end{array}$ & $\begin{array}{l}\text { Profitabilit } \\
\text { as }\end{array}$ & F1.1 & $\begin{array}{l}\text { Rasio } \\
\text { Profitabilit } \\
\text { as }\end{array}$ \\
\hline $\begin{array}{l}\text { F2 } \\
\text { Peningkatan }\end{array}$ & $\begin{array}{l}\text { Current } \\
\text { Ratio per }\end{array}$ & F2.1 & $\begin{array}{l}\text { Current } \\
\text { Ratio per }\end{array}$ \\
\hline
\end{tabular}

\begin{tabular}{|c|c|c|c|}
\hline \multirow{2}{*}{$\begin{array}{l}\text { likuiditas } \\
\text { perusahaan }\end{array}$} & \multicolumn{2}{|l|}{ periode } & periode \\
\hline & $\begin{array}{l}\text { Acid Test } \\
\text { Ratio per } \\
\text { periode }\end{array}$ & $\mathrm{F} 2.2$ & $\begin{array}{l}\text { Acid Test } \\
\text { Ratio per } \\
\text { periode }\end{array}$ \\
\hline $\begin{array}{l}\mathrm{C} 1 \\
\text { Meningkatk } \\
\text { an jumlah } \\
\text { pelanggan } \\
\text { baru }\end{array}$ & $\begin{array}{l}\text { Persentase } \\
\text { pelanggan } \\
\text { baru }\end{array}$ & C1.1 & $\begin{array}{l}\text { Persentase } \\
\text { pelanggan } \\
\text { baru }\end{array}$ \\
\hline \multirow{2}{*}{$\begin{array}{l}\text { C2 } \\
\text { Mempertaha } \\
\text { nkan } \\
\text { pelanggan } \\
\text { lama }\end{array}$} & $\begin{array}{l}\text { Customer } \\
\text { satisfactio } \\
\mathrm{n} \text { index }\end{array}$ & C2.1 & $\begin{array}{l}\text { Customer } \\
\text { satisfaction } \\
\text { index }\end{array}$ \\
\hline & $\begin{array}{l}\text { Persentase } \\
\text { pelanggan } \\
\text { tetap }\end{array}$ & C 2.2 & $\begin{array}{l}\text { Persentase } \\
\text { pelanggan } \\
\text { tetap }\end{array}$ \\
\hline $\begin{array}{l}\text { I1 } \\
\text { Peningkatan } \\
\text { kapasitas } \\
\text { produksi }\end{array}$ & $\begin{array}{l}\text { Jumlah } \\
\text { produksi } \\
\text { tiap } \\
\text { periode }\end{array}$ & I1.1 & $\begin{array}{l}\text { Jumlah } \\
\text { produksi } \\
\text { tiap } \\
\text { periode }\end{array}$ \\
\hline $\begin{array}{l}\text { I2 } \\
\text { Peningkatan } \\
\text { kualitas } \\
\text { produk }\end{array}$ & $\begin{array}{l}\text { Jumlah } \\
\text { kecacatan } \\
\text { produk }\end{array}$ & $\mathrm{I} 2.1$ & $\begin{array}{l}\text { Jumlah } \\
\text { kecacatan } \\
\text { produk }\end{array}$ \\
\hline \multirow{2}{*}{$\begin{array}{l}\text { I3 } \\
\text { Peningkatan } \\
\text { utilitas } \\
\text { mesin }\end{array}$} & $\begin{array}{l}\text { Overall } \\
\text { equipment } \\
\text { effectivene } \\
\text { ss }\end{array}$ & I3.1 & $\begin{array}{l}\text { Overall } \\
\text { equipment } \\
\text { effectivene } \\
\text { ss }\end{array}$ \\
\hline & $\begin{array}{l}\text { Jam kerja } \\
\text { mesin }\end{array}$ & I3.2 & $\begin{array}{l}\text { Jam kerja } \\
\text { mesin }\end{array}$ \\
\hline $\begin{array}{l}\text { I4 } \\
\text { Peningkatan } \\
\text { efisiensi } \\
\text { produksi }\end{array}$ & $\begin{array}{l}\text { Tingkat } \\
\text { efisiensi } \\
\text { Produksi }\end{array}$ & I4.1 & $\begin{array}{l}\text { Tingkat } \\
\text { efisiensi } \\
\text { Produksi }\end{array}$ \\
\hline $\begin{array}{l}\text { L1 } \\
\text { Peningkatan } \\
\text { kompetensi } \\
\text { karyawan }\end{array}$ & $\begin{array}{l}\text { Jumlah } \\
\text { pelatihan } \\
\text { kompetens } \\
\text { i karyawan } \\
\end{array}$ & L1.1 & $\begin{array}{l}\text { Jumlah } \\
\text { pelatihan } \\
\text { kompetens } \\
\text { i karyawan }\end{array}$ \\
\hline \multirow{2}{*}{$\begin{array}{l}\text { L2 } \\
\text { Peningkatan } \\
\text { lingkungan } \\
\text { kerja } \\
\text { kondusif }\end{array}$} & $\begin{array}{l}\text { Persentase } \\
\text { Flexibility } \\
\text { comformit } \\
\text { y }\end{array}$ & L2.1 & $\begin{array}{l}\text { Persentase } \\
\text { Flexibility } \\
\text { comformit } \\
\text { y }\end{array}$ \\
\hline & $\begin{array}{l}\text { Tingkat } \\
\text { komunikas } \\
\text { i dari } \\
\text { karyawan } \\
\text { hingga } \\
\text { atasan }\end{array}$ & L2.2 & $\begin{array}{l}\text { Tingkat } \\
\text { komunikas } \\
\text { i dari } \\
\text { karyawan } \\
\text { hingga } \\
\text { atasan }\end{array}$ \\
\hline $\begin{array}{l}\text { L3 } \\
\text { Peningkatan } \\
\text { produktifitas } \\
\text { karyawan }\end{array}$ & $\begin{array}{l}\text { Tingkat } \\
\text { produktifit } \\
\text { as } \\
\text { karyawan } \\
\text { per } \\
\text { periode }\end{array}$ & L3.1 & $\begin{array}{l}\text { Tingkat } \\
\text { produktifit } \\
\text { as } \\
\text { karyawan } \\
\text { per periode }\end{array}$ \\
\hline
\end{tabular}




\begin{tabular}{|c|c|c|c|}
\hline $\begin{array}{l}\text { L4 } \\
\text { Peningkatan } \\
\text { kesejahteraa } \\
\text { n karyawan }\end{array}$ & $\begin{array}{l}\text { Jaminan } \\
\text { kesehatan } \\
\text { karyawan }\end{array}$ & L4.1 & $\begin{array}{l}\text { Jaminan } \\
\text { kesehatan } \\
\text { karyawan }\end{array}$ \\
\hline
\end{tabular}

\subsection{Pembobotan Menggunakan Model Analytical Network Process}

Setelah melakukan perancangan dengan menggunakan metode Balanced Scorecard untuk mendapatkan KPI, tahap selanjutnya yaitu perancangan dengan menggunakan Analytical Network Process. Dalam perancangannya, data KPI dari model BSC kemudian akan diolah dengan menggunakan model ANP.

Pembobotan KPI bertujuan untuk menentukan tingkat kepentingan berdasarkan KPI yang telah ditentukan sebelumnya. Dalam melakukan pembobotan KPI, model yang akan digunakan adalah Analytical Network Process (ANP). Model ini menggunakan software Super Decision 2.0. Pada proses pembobotan, data dikumpulkan dalam hasil wawancara dengan pihak yang dianggap berkompeten dan memahami kondisi perusahaan secara real yaitu Manager HRD perusahaan. Hasil dari wawancara kemudian diolah untuk mendapatkan bobot kepentingan kinerja perusahaan. Hasil pembobotan dapat dilihat pada tabel 4

Tabel 4. Pembobotan Perspektif BSC

\begin{tabular}{|c|c|c|}
\hline \multicolumn{2}{|c|}{ Cluster Node Label } & Score \\
\hline \multirow{4}{*}{ Criteria } & Financial & 0.28 \\
\hline & Customer & 0.238 \\
\hline & $\begin{array}{l}\text { Internal } \\
\text { Business }\end{array}$ & 0.296 \\
\hline & $\begin{array}{l}\text { Learning } \\
\text { Growth }\end{array}$ & 0.186 \\
\hline \multirow{9}{*}{ KPI } & F1.1 & 0.244 \\
\hline & F2.1 & 0.023 \\
\hline & $\mathrm{F} 2.2$ & 0.013 \\
\hline & $\mathrm{C} 1.1$ & 0.142 \\
\hline & $\mathrm{C} 2.1$ & 0.052 \\
\hline & $\mathrm{C} 2.2$ & 0.044 \\
\hline & I1.1 & 0.116 \\
\hline & $\mathrm{I} 2.1$ & 0.08 \\
\hline & I3.1 & 0.018 \\
\hline
\end{tabular}

\begin{tabular}{ll}
\hline I3.2 & 0.03 \\
\hline I4.1 & 0.052 \\
\hline L1.1 & 0.052 \\
\hline L2.1 & 0.017 \\
\hline L2.2 & 0.013 \\
\hline L3.1 & 0.084 \\
\hline L4.1 & 0.02 \\
\hline re & 0.244
\end{tabular}

Sumber: Hasil Pengolahan Data 2019

Berdasarkan tabel di atas, dapat diketahui bahwa internal business memiliki score tertinggi dengan nilai 0.296 yang diikuti oleh aspek financial dengan score 0.28, customer dengan score 0.238 , dan terakhir yaitu learning \& growth dengan score 0.186. Dari hasil di atas, maka internal business memiliki pengaruh besar pada sistem pengukuran kinerja. Selnajutnya pembobotan pada tiap faktor dengan score tertinggi terdapat pada F1.1 yaitu persentase ratio profitabilitas dengan skor sebesar 0.244. Sedangkan faktor dengan nilai terendah terdapat pada fakor F2.2 yaitu acid test ratio per periode serta L2.2 yaitu tingkat komunikasi antar karyawan dimana memiliki skor masing-masing sebesar 0.013 .

\subsection{Pengukuran Kinerja Menggunakan Objective Matrix (OMAX)}

Pada poin ini, analisa dilakukan pada proses pengukuran kinerja menggunakan $O M A X$ dan Traffic Lines System. Berdasarkan pengukuran menggunakan metode OMAX dan TLS, beberapa KPI masih berada di bawah rata-rata yang diinginkan oleh perusahaan. Adapun hasil pengukuran KPI dapat dilihat pada tabel 5-6.

Tabel 5. Nilai KPI Pada OMAX 1

\begin{tabular}{|l|c|}
\hline \multicolumn{1}{|c|}{ Aspek } & Nilai KPI \\
\hline Financial & 1.472 \\
\hline Customer & 1.228 \\
\hline Internal Business & 1.526 \\
\hline Learning and Growth & 0.71 \\
\hline \multicolumn{1}{|c|}{ Total } & 4.936 \\
\hline
\end{tabular}

Sumber: Hasil Pengolahan Data 2019 
Tabel 6. Hasil KPI Pada OMAX 2

\begin{tabular}{|l|c|c|c|}
\hline \multirow{2}{*}{\multicolumn{1}{|c|}{ Faktor }} & \multicolumn{3}{c|}{ Pencapaian } \\
\cline { 2 - 4 } & Baik & Cukup & Kurang \\
\hline Financial & 0 & 3 & 0 \\
\hline Customer & 0 & 2 & 1 \\
\hline Internal Business & 2 & 1 & 2 \\
\hline Learning and growth & 1 & 2 & 2 \\
\hline \multicolumn{1}{|c|}{ Total } & 3 & 8 & 5 \\
\hline
\end{tabular}

Sumber: Hasil Pengolahan Data 2019

Dari tabel 6, diketahui bahwa terdapat 3 KPI yang telah sesuai dengan target. Selain itu, terdapat pula 8 KPI yang berada di tingkat rata-rata atau cukup serta 5 KPI yang dianggap masih kurang. Maka dari itu, untuk mengatasi kurangnya tingkat kinerja perusahaan, maka akan dilakukan evaluasi dan perbaikan.

\subsection{Evaluasi Menggunakan Traffic Line System}

Berdasarkan evaluasi menggunakan TLS, KPI berwarna merah dianggap masih kurang. Sehingga KPI-KPI tersebut perlu diperbaiki untuk meningkatkan kinerja perusahaan. Adapun untuk KPI berwarna kuning berarti berada pada rata-rata kinerja perusahaan. KPI ini dianggap baik, akan tetapi diperlukan perbaikan lagi untuk meningkatkan kinerja perusahaan. Sedangkan KPI berwarna hijau berarti telah sesuai dengan target perusahaan. Adapun hasil model TLS dapat dilihat pada tabel 7.

Tabel 7. Hasil Evaluasi Dengan TLS

\begin{tabular}{|c|c|c|c|c|}
\hline $\begin{array}{l}\text { Kod } \\
\text { e }\end{array}$ & $\begin{array}{l}\text { Key } \\
\text { Performanc } \\
\text { e Indicators }\end{array}$ & $\begin{array}{l}\text { Bobo } \\
\text { t }\end{array}$ & $\begin{array}{l}\text { Pencapaia } \\
\text { n }\end{array}$ & $\begin{array}{l}\text { Ran } \\
\mathbf{k}\end{array}$ \\
\hline F1.1 & $\begin{array}{l}\text { Rasio } \\
\text { Profitabilitas }\end{array}$ & 0.244 & 50.270 & 5 \\
\hline F2.1 & $\begin{array}{l}\text { Current } \\
\text { Ratio per } \\
\text { periode }\end{array}$ & 0.023 & 95.294 & 7 \\
\hline F2.2 & $\begin{array}{lr}\text { Acid } & \text { Test } \\
\text { Ratio } & \text { per } \\
\text { periode } & \end{array}$ & 0.013 & 77.647 & 7 \\
\hline C1.1 & $\begin{array}{l}\text { Persentase } \\
\text { pelanggan } \\
\text { baru }\end{array}$ & 0.142 & 20 & 6 \\
\hline
\end{tabular}

\begin{tabular}{|c|c|c|c|c|}
\hline $\mathrm{C} 2.1$ & $\begin{array}{l}\text { Customer } \\
\text { satisfaction } \\
\text { index }\end{array}$ & 0.052 & 47.5 & 3 \\
\hline $\mathrm{C} 2.2$ & $\begin{array}{l}\text { Persentase } \\
\text { pelanggan } \\
\text { tetap }\end{array}$ & 0.044 & 55 & 5 \\
\hline I1.1 & $\begin{array}{l}\text { Jumlah } \\
\text { produksi } \\
\text { tiap periode }\end{array}$ & 0.116 & 365.200 & 3 \\
\hline $\mathrm{I} 2.1$ & $\begin{array}{l}\text { Jumlah } \\
\text { kecacatan } \\
\text { produk }\end{array}$ & 0.08 & 0.744 & 7 \\
\hline I3.1 & $\begin{array}{l}\text { Overall } \\
\text { equipment } \\
\text { effectiveness }\end{array}$ & 0.018 & 79.039 & 9 \\
\hline $\mathrm{I} 3.2$ & $\begin{array}{ll}\text { Jam kerja } \\
\text { mesin }\end{array}$ & 0.03 & 480 & 10 \\
\hline I4.1 & $\begin{array}{l}\text { Tingkat } \\
\text { efisiensi } \\
\text { Produksi }\end{array}$ & 0.052 & 50.918 & 3 \\
\hline L1.1 & $\begin{array}{l}\text { Jumlah } \\
\text { pelatihan } \\
\text { kompetensi } \\
\text { karyawan } \\
\end{array}$ & 0.052 & 78 & 2 \\
\hline $\mathrm{L} 2.1$ & $\begin{array}{l}\text { Persentase } \\
\text { karir } \\
\text { karyawan }\end{array}$ & 0.017 & 34 & 6 \\
\hline $\mathrm{L} 2.2$ & $\begin{array}{l}\text { Tingkat } \\
\text { komunikasi } \\
\text { dari } \\
\text { karyawan } \\
\text { hingga } \\
\text { atasan }\end{array}$ & 0.013 & 56.67 & 4 \\
\hline L3.1 & $\begin{array}{l}\text { Tingkat } \\
\text { produktifitas } \\
\text { karyawan } \\
\text { per periode }\end{array}$ & 0.084 & 987 & 3 \\
\hline L4.1 & $\begin{array}{l}\text { Jaminan } \\
\text { kesehatan } \\
\text { karyawan }\end{array}$ & 0.02 & 2.700 .000 & 10 \\
\hline
\end{tabular}

Sumber: Hasil Pengolahan Data 2019

Berdasarkan tabel 7, maka warna hijau dianggap sudah baik karena sudah sesuai dengan pencapaian perusahaan. Warna kuning dianggap rata-rata dan warna merah dianggap kurang. Adapun untuk warna kuning-kuning diperlukan perbaikan meskipun sudah pencapaian memiliki nilai rata-rata. Sedangkan warna nerah yang dianggap kurang, maka diperlukan perbaikan untuk meningkatkan kinerjanya. 
Adapun usulan perbaikan ini berdasarkan evaluasi pada hasil tabel OMAX yang dianggap kurang. Adapun perbaikan yang akan diusulkan seperti pada tabel 8 mengenai usulan perbaikan kinerja perusahaan.

Tabel 8. Usulan Perbaikan Kinerja

\begin{tabular}{|c|c|}
\hline Aspek & Usulan Perbaikan \\
\hline \multirow{3}{*}{ Financial } & $\begin{array}{l}\text { Memperbanyak target penjualan } \\
\text { kepada konsumen }\end{array}$ \\
\hline & $\begin{array}{l}\text { Menambah target pelanggan baru } \\
\text { bagi perusahaan }\end{array}$ \\
\hline & $\begin{array}{l}\text { Memperbanyak produk yang akan } \\
\text { diproduksi untuk meningkatkan } \\
\text { pemasukan ke perusahaan }\end{array}$ \\
\hline \multirow{3}{*}{ Customer } & $\begin{array}{l}\text { Mempertahankan kualitas produk } \\
\text { yang dipesan oleh pelanggan }\end{array}$ \\
\hline & $\begin{array}{l}\text { Survei pelanggan mengenai } \\
\text { kebutuhan dan keinginan pelanggan } \\
\text { terhadap produk yang dipesan }\end{array}$ \\
\hline & $\begin{array}{l}\text { Memberikan jaminan produk yang } \\
\text { akan dipesan oleh pelanggan }\end{array}$ \\
\hline \multirow{3}{*}{$\begin{array}{l}\text { Internal } \\
\text { Business }\end{array}$} & $\begin{array}{l}\text { Menambah jumlah produk paad tiap } \\
\text { periode }\end{array}$ \\
\hline & $\begin{array}{l}\text { Melakukan inspeksi terhadap tiap } \\
\text { produk secara ketat untuk } \\
\text { menghindari adanya kecacatan } \\
\text { produk yang terlalu banyak }\end{array}$ \\
\hline & $\begin{array}{l}\text { Mengurangi adanya waste saat proses } \\
\text { produksi baik waktu, bahan baku, } \\
\text { hingga produk jadi }\end{array}$ \\
\hline \multirow{3}{*}{$\begin{array}{l}\text { Learning } \\
\text { and } \\
\text { Growth }\end{array}$} & $\begin{array}{l}\text { Memperbanyak pelatihan karyawan } \\
\text { untuk meningkatkan kemampuan } \\
\text { karyawan serta pemberian job } \\
\text { enrichment pada karyawan dengan } \\
\text { jabatan yang sama }\end{array}$ \\
\hline & $\begin{array}{l}\text { Memberikan fasilitas untuk karyawan } \\
\text { serta mengadakan rapat wajib seluruh } \\
\text { karyawan }\end{array}$ \\
\hline & $\begin{array}{l}\text { Memberikan target produksi untuk } \\
\text { tiap karyawan }\end{array}$ \\
\hline
\end{tabular}

Sumber: Hasil Pengolahan Data 2019

\section{Kesimpulan dan Saran}

Berdasarkan hasil pengukuran KPI menggunakan OMAX, maka didapatkan 3 KPI berwarna hijau atau sesuai dengan pencapaian, yaitu: overall equipment effectiveness, jam kerja mesin, dan jaminan kesehatan karyawan,
8 KPI berwarna kuning atau rata-rata, yaitu: rasio profitabilitas, current ratio per periode, acid test ratio per periode, persentase pelanggan baru, persentase pelanggan tetap, jumlah kecacatan produk, persentase karir karyawan, dan tingkat komunikasi dari karyawan hingga atasan, serta 5 KPI berwarna merah yang dianggap kurang,yaitu: tingkat kepuasan pelanggan (customer satisfaction index), jumlah produksi tiap periode, tingkat efisiensi produksi, jumlah pelatihan kompetensi karyawan, dan tingkat produktifitas karyawan per period. Untuk KPI berwarna hijau dianggap baik sehingga tidak perlu dilakukan perbaikan. Perbaikan kinerja dilakukan pada beberapa KPI yang dianggap kurang atau berwarna merah serta KPI yang dianggap sedang atau berwarna kuning. Adapun nilai overall performancedari kinerja perusahaan sebesar 4.936. Nilai ini berarti perusahaan masih berada rata-rata dari nilai 1 hingga 10. Adapun perbaikan yang dapat digunakan untuk perusahaan yaitu melakukan pengukuran kinerja secara berkala serta meningkatkan kinerja tiap aspek. Perbaikan bisa berupa perbaikan sistem yang terdapat di perusahaan.

\section{Daftar Pustaka}

[1] I. Vanany, "Aplikasi Analytic Network Process (ANP) pada perancangan sistem pengukuran kinerja (studi kasus pada PT. X)," Jurnal Teknik Industri, vol. 5, no. 1, pp. 50-62, 2003.

F. A. Atmaja, I. Soejanto, and I. Berlianty, "PENGUKURAN TINGKAT KINERJA PERUSAHAAN MENGGUNAKAN METODE BALANCED SCORECARD DAN ANALYTIC NETWORK PROCESS," in Prosiding Seminar Nasional Waluyo Jatmiko 2015, 2015: Fakultas Teknologi Industri UPN" Veteran" Jatim, pp. P. 01-P. 19.

[3] S. Sapto, "Aplikasi Analytic Network Process Pada Perancangan Sistem Pengukuran Kinerja dengan Menggunakan Metode Balanced Scorecard," Jurnal Teknik Industri, vol. 9, no. 2, pp. 137-146, 2009. 
[4] R. S. Kaplan and D. P. Norton, "The balanced scorecard: measures that drive performance," 1992.

[5] R. S. Kaplan, T. H. Davenport, N. P. D. K. S. Robert, R. S. Kaplan, and D. P. Norton, The strategy-focused organization: How balanced scorecard companies thrive in the new business environment. Harvard Business Press, 2001.

[6] T. L. Saaty, "Fundamentals of the analytic network process," in Proceedings of the 5th international symposium on the analytic hierarchy process, 1999, pp. 1214.

[7] T. L. Saaty, Decision making with dependence and feedback: The analytic network process. RWS Publ., 1996.

[8] Kaplan, R. S., \& Norton, D. P. (1992). The balanced scorecard: measures that drive performance. 